Marta Róg ${ }^{1}$, Antoni Rzonca ${ }^{2}$

\title{
The Impact of Photo Overlap, the Number of Control Points and the Method of Camera Calibration on the Accuracy of 3D Model Reconstruction ${ }^{3}$
}

\begin{abstract}
This research attempted to determine the optimal photo overlap, number of control points and method of camera calibration for a photogrammetric 3D model reconstruction of an object of cultural heritage value. Terrestrial images of the object were taken with a hand-held digital camera and processed in the ContextCapture software using the Structure-from-Motion (SfM) algorithm. A total station was used to measure ground control points (GCPs) and check points. Here, the research workflow, methodology, and various analyses concerning different configurations of the aforementioned factors are described. An attempt to assess the parameters which should be implemented in order to provide a high degree of accuracy of the model and reduce time-consumption both during fieldwork and data processing was taken. The manuscript discusses the results of the analyses and compares them with other studies presented by different authors and indicates further potential directions of studies within this scope. Based on the authors' experience with this research, some general conclusions and remarks concerning the planning of photo acquisition from the terrestrial level for the purpose of 3D model reconstruction were formulated.
\end{abstract}

Keywords: SfM algorithm; 3D reconstruction, close range photogrammetry; accuracy assessment; photogrammetric network parameters

Received: 10 December 2020; accepted: 18 February 2021

(C) 2021 Authors. This is an open access publication, which can be used, distributed and reproduced in any medium according to the Creative Commons CC-BY 4.0 License.

1 AGH University of Science and Technology, Faculty of Mining Surveying and Environmental Engineering, Krakow, Poland, email: martarog@agh.edu.pl

ORCID ID: https://orcid.org/0000-0001-6126-7524,

2 AGH University of Science and Technology, Faculty of Mining Surveying and Environmental Engineering, Krakow, Poland, email: arz@agh.edu.pl

ORCID ID: https://orcid.org/0000-0003-0333-1000

3 The article was prepared under the research subvention of AGH University of Science and Technology No. 16.16.150.545 


\section{Introduction}

Structure-from-Motion (SfM) algorithms are currently commonly used in many different fields of science [1]. Thanks to the rapid development of new technologies and the increasing power of computer and mobile devices over the past decade, they have become much more accessible and their advancing accuracy is comparable to that obtained using traditional methods [2]. Photogrammetric 3D modeling based on the SfM algorithm may be, among others, used for the purpose of architectural visualization [3], archaeology [4, 5], environmental and climate monitoring [6, 7], geomorphology [8], medicine [9, 10]. The SfM method is also the leading one in cultural heritage recording [11] because of several factors: contactless method of data acquisition, no need to carry bulky tools to remote and hard to reach regions, high degree of accuracy and the relatively low costs of this method [12-14]. Nowadays, photogrammetric methods based on SfM are also commonly used in augmented and virtual reality, something which becoming a pressing issue in cultural heritage studies [15] and its alternative representations on the Web [16]. Photos may be acquired from both the terrestrial level (close-range photogrammetry) - with a hand-held digital (non-metric) camera and from the aerial level - when the camera is attached to an unmanned aerial vehicle (UAV) $[17,18]$. The general principles of the SfM method remain valid for both aforementioned approaches [19]. Not only can we use traditional images, but software with the SfM algorithms allow for processing spherical panoramas, which may be particularly useful in indoor measurements [20].

The SfM algorithm is based on the same assumption as traditional stereoscopic photogrammetry - a 3D structure of terrain or object is retrieved thanks to the overlapping photographs [21]. The main difference is that, thanks to the SfM algorithms, the process of aligning the photos may be fully automated - there is no need to provide camera calibration parameters, camera positions and orientation or definition of control points [19, 21]. However, the user can decide to import some of those parameters to enhance the photo network, georeference the model or establish the scale. The SfM algorithms detect characteristic points on images and monitor their movement throughout the photoset, which allows their locations to be estimated. A sparse point cloud and information about camera positions and calibration are the results of the first stage of the SfM algorithm implementation, afterwards a dense point cloud can be generated [22]. Furthermore, different approaches towards the implementation of the SfM algorithm may be found in various photogrammetric software $[12,19]$. The scope of this manuscript does not allow to fully explore the topic of the SfM algorithm. Further valuable information may be found in the papers in the domain of photogrammetry and computer vision, e.g. [19, 21, 23, 24].

This paper focuses on the photo network optimization acquired with a digital hand-held camera regarding photo resolution, number of control points, camera calibration methods and the overlap percentage between adjacent images. The measures of accuracy were the same as those used for assessing the process of aerial 
triangulation in commonly used photogrammetric software and were based on root mean square (RMS) errors obtained on ground control points (GCPs) and check points [25-27], whose local metric coordinates were determined thanks to the measurements conducted with a total station. In the Discussion section of this paper we compared our results with other studies concerning the following aspects: camera calibration method [28], number and distribution of ground control points [29-31], overlap of the photographs [32]. At this point, it is worth noting that the conditions of the analysis were not laboratory ones since the aim of this research was to develop some general conclusions that would apply in the real world for an average user. We believe it is an important study as there are few studies concerning these issues with regards close-range photogrammetry.

\section{Object of Research and Research Workflow}

The object of the research was the base of the former monument of Ivan Konev located in Bronowice-Widok district, Kraków, Poland (Fig. 1).

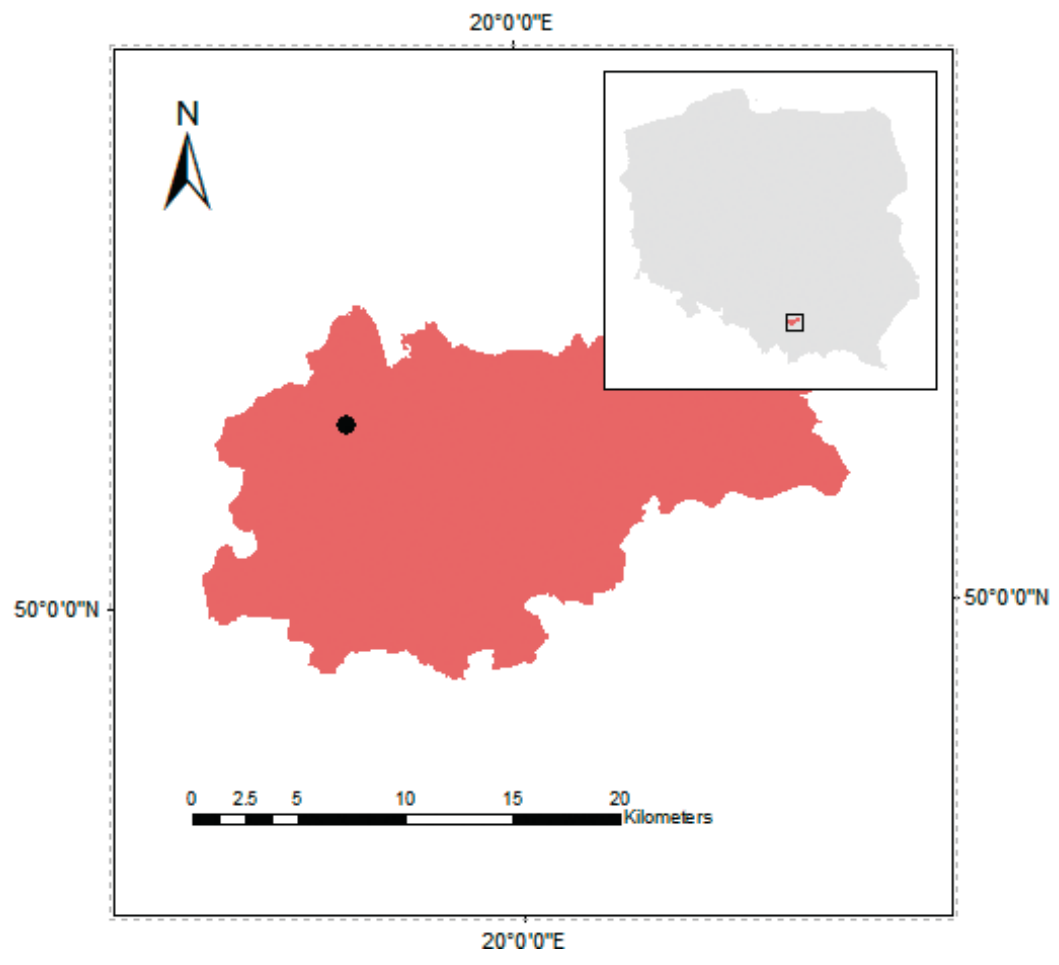

Fig. 1. Location of the object of research; red - the city of Kraków, gray - the contour of Poland

Source: elaboration with the use of free data from the National Register of Boundaries 
Konev was the marshal of the Soviet Union and the leader of the First Ukrainian Front who captured the city of Kraków in 1945, forcing German soldiers to surrender [33]. After World War II, Poland was dominated by the Soviet Union and governed by the communist Polish Workers' Party, holding the name of the Polish People's Republic between 1952 and 1989. During this period, Ivan Konev was honored for 'liberation and saving the city of Kraków' with the Virtuti Militari order. One of the main streets in Kraków was given his name, as was a newly founded school. According to historic research, this was just an element of propaganda as the intentions of Konev when entering Kraków were simply strategic and military. The monument of Ivan Konev designed by Antoni Hajdecki was unveiled on the $18^{\text {th }}$ of January 1987, many years after World War II, and was clearly visible from one of the major streets. It was disassembled in 1991, after the decommunization of Poland and the figure of Ivan Konev was sent to Kirov, Russia - the region of Konev's birth [33, 34]. However, the base of the monument was left untouched (Fig. 2) due to its historic and aesthetic values, a decision supported by the main architect of the Widok district, the Society of Polish Architects and the Conservation Officer of Kraków [33].

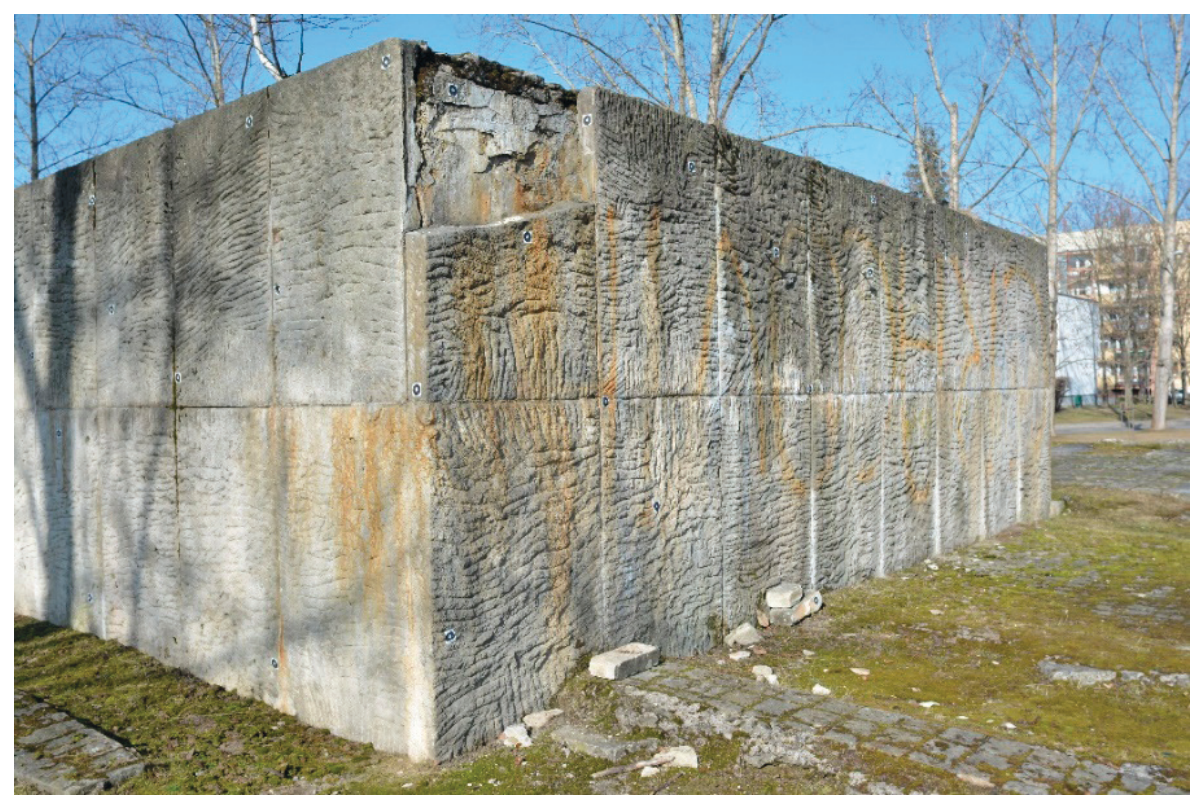

Fig. 2. Object of research (phot. Marta Róg)

The base is made of quasi-regular blocks of stone with the total size of approximately $8 \mathrm{~m} \times 5 \mathrm{~m}$. For the purpose of this research, we took photographs of two adjacent walls. The object was chosen due to its accessibility for photo acquisition from different distances (photo resolution aspect) and its quite regular shape with 
protruding elements such as metal rods or stones and holes. Bearing in mind the more frequent use of photogrammetric methods for building reconstruction, we also took under consideration the size of the object.

The research was divided into three main parts. The first one covered fieldwork, including camera calibration, measurements and photo acquisition. The second stage was conducted with the use of photogrammetric software and involved a 3D reconstruction of the object with different variants and configurations of changeable factors. The third part of the study focused on the analysis of the accuracy values obtained in particular variants and their visualization. We will describe the particular steps in the forthcoming parts of this manuscript.

\section{Research Workflow - Fieldwork}

Before the photo acquisition we performed the camera calibration of a Nikon D5200: a hand-held, digital single-lens reflex camera. It was conducted on a dedicated test field, printed out from the website of the PI-Calib software producer. This software was developed by Topcon Corporation and currently is known as Topcon's Imagemaster Calib. It allows for performing calibration and calculating 7 parameters: focal length (f), radial and tangential distortion (K1, K2, P1, P2) and location of principle point $\left(X_{p^{\prime}} Y_{p}\right)$. The test field consists of 145 dots and 5 squares, 5 dots in squares are considered standard marks and are used by the software for main calculations [35].

The images were taken in accordance with specific guidelines -5 photographs in total, from the front, left, right, look-down and look-up angle, and then imported into the software. It was necessary to specify the size of the test field sheet used and measure standard marks in the software. The parameters allowing for the determination of bundle trajectory inside the camera were computed along with a radial and tangential model of distortion. They were stored in a calibration report and then could be manually implemented in the ContextCapture software. The focal length was stabilized prior to the camera calibration process at $20 \mathrm{~mm}$ and the focusing distance was adjusted to an average photography shooting distance. Then, the aperture was changed during the fieldwork in order to obtain good focus on all distances considering planned GSDs. These focusing conditions were preserved throughout the analysis thanks to using adhesive tape preventing from changing the parameters. According to the calibration report, the focal length equaled $19.97 \mathrm{~mm}$. The overall accuracy of this process (mean value of $0.24 \mathrm{~mm}$ ) was automatically calculated by the software based on residuals obtained on test field points in the directions of coordinate system axes $-X, Y, Z$.

The next step covered the distribution of artificial control points on the object of research. These were black and white targets with a clearly marked cross in their middle, in the size allowing for its precise identification both during works in the 
field and data processing (Fig. 3). The targets were attached both to the main form of the object and to protruding elements such as stones or metal rods. They were distributed evenly on two faces of the object in a total number of 35-20 on the longer wall and 15 on the shorter one. All points used are presented schematically in relation to the longer and shorter walls (Fig. 4). The figure shows a configuration used in the majority of our analyses -26 control points (yellow) and 8 check points (red) presented on an exemplary mesh model produced during the research.
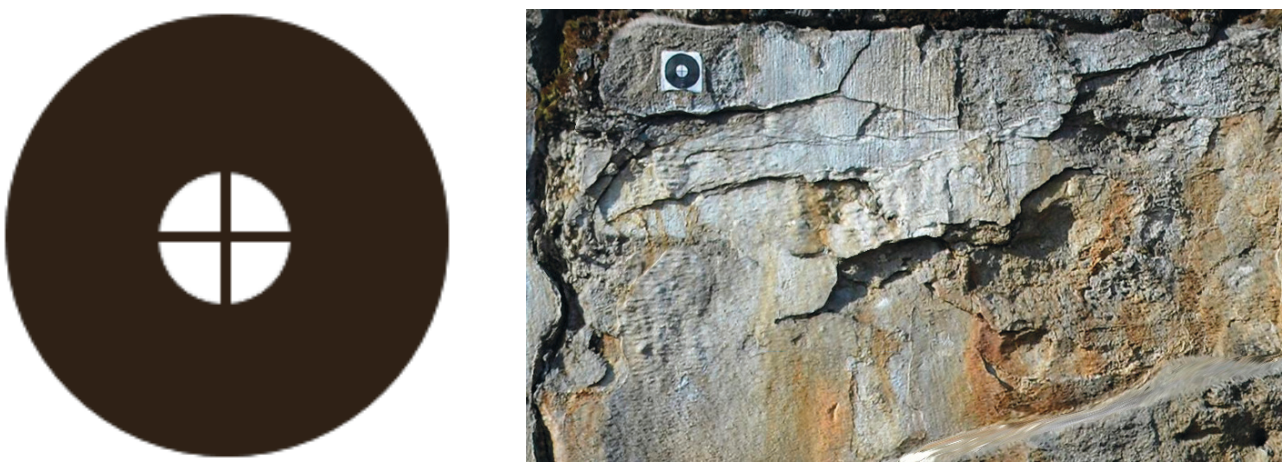

Fig. 3. Black and white targets that served as GCPs and check points

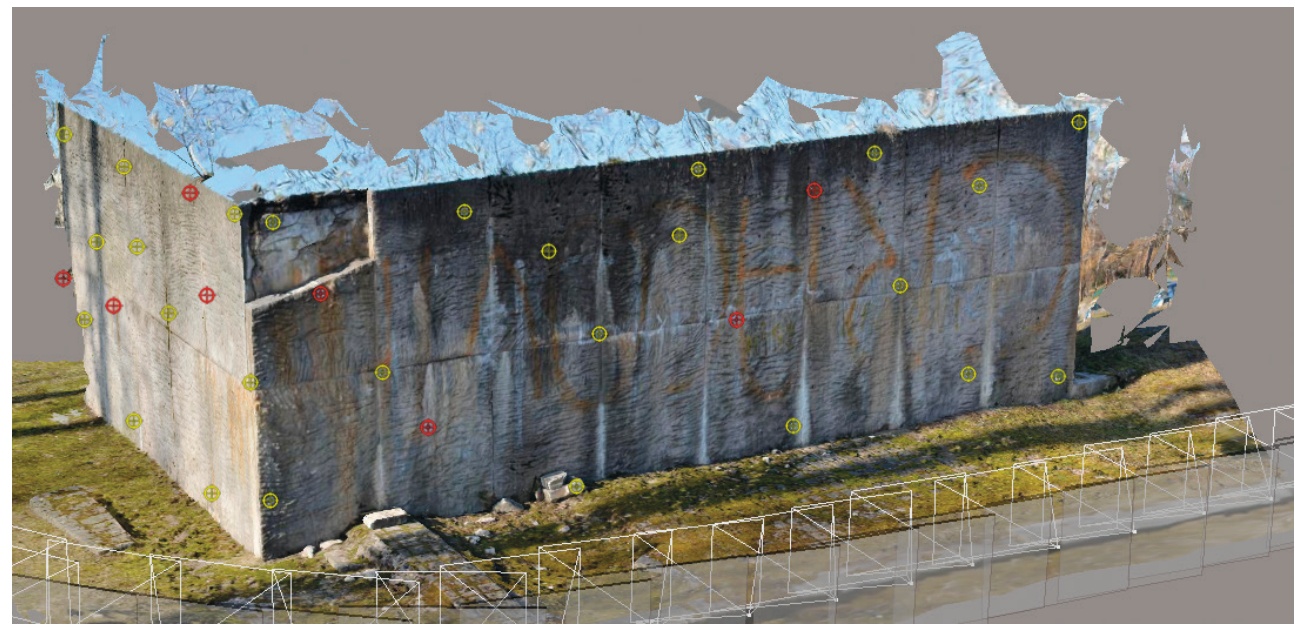

Fig. 4. Control points (yellow) and check points (red) on an exemplary mesh model produced in ContextCapture

The control points were measured using a total station with reflectorless mode Topcon OS 103 - in two rounds and two faces from two instrument positions of known local coordinates calculated on the basis of the observations. These instrument positions were treated as referential, the difference in height and distance 
was checked independently to provide as high a degree of accuracy of the control points measurements as possible. All calculations were performed in the C-Geo software. Control points were based on total station measurements in a tachymetry mode and their coordinates were calculated using a mean value of 4 observations. Standard deviations of distances from stations to particular points did not exceed $1 \mathrm{~mm}$, with a mean value of $0.3 \mathrm{~mm}$ for the first station and $0.5 \mathrm{~mm}$ for the second station. Mean standard deviations of angular measurements equaled $0.0023^{\circ}$ for the first station and $0.0030^{\mathrm{g}}$ for the second station. Taking into consideration the distance from the stations to points: $6.907-8.462 \mathrm{~m}$ from the first station (a shorter wall) and $6.020-7.428 \mathrm{~m}$ (a longer wall), we calculated the possible error in metric units using the formula $x / 8.462=\tan \left(0.0023^{\circ}\right), x=0.3 \mathrm{~mm}$ and $y / 7.428=\tan \left(0.0030^{\circ}\right)$, $y=0.4 \mathrm{~mm}$. Given these calculations, the possible error of the measurements from the first station was $0.4 \mathrm{~mm}$ and $0.6 \mathrm{~mm}$ from the second station. Due to possible similar errors on the referential points, we decided to set the control point accuracy to $1 \mathrm{~mm}$ in ContextCapture, however test calculations have also been run for $0.5 \mathrm{~mm}$ and $3 \mathrm{~mm}$ accuracy.

The whole process of the work in the field was preceded by a careful planning of the photo acquisition so that the desired resolution of the images could have been achieved. The images were taken with three different Ground Sample Distances (GSDs) $-1 \mathrm{~mm}, 0.75 \mathrm{~mm}$ and $0.5 \mathrm{~mm}$ and providing the maximum overlap of $90 \%$. It allowed a future analysis to be conducted on four different photosets overlapping by $90 \%, 80 \%, 70 \%$ and $60 \%$. All distances (between adjacent images and from the baseline to the object) were determined mathematically (Tab. 1) and applied during fieldwork by using a measurement tape. The photos were taken with a camera held in the hand, without a tripod. The focal length of the camera was set as stable while other parameters, such as aperture, ISO and shutter speed, were adjusted according to the light conditions but did not differ within the photoset taken with one spatial resolution. The total number of images captured with $0.5 \mathrm{~mm}$ resolution was 190 as the overlap in vertical direction was also required, in the photoset with $0.75 \mathrm{~mm}$ resolution there were 108 photos and in $1 \mathrm{~mm}$ resolution - 34 .

Table 1. Photo acquisition planning

\begin{tabular}{|c|c|c||}
\hline Planned GSD [mm] & Distance to the object [m] & $\begin{array}{c}\text { Distance between images overlapping by 90\% } \\
{[\mathrm{m}]}\end{array}$ \\
\hline \hline 0.5 & 2.56 & 0.30 \\
\hline 0.75 & 3.84 & 0.45 \\
\hline 1.0 & 5.12 & 0.60 \\
\hline
\end{tabular}




\section{Research Workflow - Data Processing}

The main part of this research was conducted in the Bentley Systems' product - Bentley Context Capture - which allows for creating 3D model reconstructions based on a set of overlapping photographs. The process each time covered several steps that differed in the number of included images, ground control points and check points. For more thorough analysis the method of camera calibration was also modified. All variants of the analysis will be described in the following sections.

First of all, it was necessary to import images to an empty block. For every dataset involving different photographs it was essential to conduct measurements of control points and check points, indicate them on the images and assign them one of the available categories. The coordinates calculated after the fieldwork were imported to the software to enable the accuracy assessment of the whole process, the accuracy of control points was set to $1 \mathrm{~mm}$ as measurements suggest. However, we also run test alignments for $0.5 \mathrm{~mm}$ and $3 \mathrm{~mm}$ accuracy. The lower assumed degree of accuracy of control points resulted in much worse accuracy parameters and higher accuracy produced highly unstable and unpredictable results. This suggests that one should pay attention while setting control points accuracy in Context Capture in order to reflect real conditions.

It was necessary to provide some additional information about the project before the aerotriangulation process. The block type was chosen as Generic, which means that the photographs overlap and that their base is approximately parallel. This parameter remained invariable in each analysis. The next important step was the aerotriangulation whose result is a sparse point cloud. In order to conduct the aerotriangulation effectively it was necessary to choose right options with regards to the type of dataset. In the case of this project, georeferencing was carried out with the use of control points for adjustment, which is recommended for accurate measurements. Key point density was set to normal - as for large datasets the aerotriangulation process tends to be very time-consuming and hardware-demanding. The pair selection mode was set to default and automatic color equalization was enabled. The parameters of the camera differed in some combinations depending on the chosen method of camera calibration.

After successful process of aerotriangulation and positive accuracy assessment it was possible to create 3D mesh models based on sparse point clouds for each configuration.

\section{Results - Overlap}

The first analysis concerned the impact of the overlap on the final model accuracy. We carried out this study for photo groups with different spatial resolution $1 \mathrm{~mm}, 0.75 \mathrm{~mm}$ and $0.5 \mathrm{~mm}$. Adjacent images overlapped by $90 \%, 80 \%, 70 \%$ and $60 \%$. 
All these calculations were performed with the use of 26 GCPs and 8 check points. However, each time one GCP changed due to technical problems (displacement between taking the photos for different variants) or because of too weak visibility (1 mm resolution photographs). 8 check points remained stable for the images with $1 \mathrm{~mm}$ and $0.75 \mathrm{~mm}$ resolution. One of them changed in the photo group with $0.5 \mathrm{~mm}$ resolution. There were 4 evenly distributed check points on each side of the object. In this analysis the aerotriangulation was performed with the use of camera self-calibration method. The results are presented in Table 2 and corresponding figures. In Figure 5 we can see the internal accuracy described by the RMSE value obtained on GCPs and in Figure 6 - the external accuracy based on the discrepancies between real coordinates of check points measured in the field and those calculated on the reconstructed model. The quality of the aerotriangulation process itself may also be assessed based on reprojection error (pix) on all tie points after alignment. In the case of this project the values varied between 0.40 and 0.54 pixels.

Table 2. Accuracy of the aerotriangulation for different overlap values

\begin{tabular}{|c|c|c|c|c|c|c|c|c|c|c|c|c|}
\hline Parameter & \multicolumn{4}{|c|}{$\mathrm{GSD}=1 \mathrm{~mm}$} & \multicolumn{4}{|c|}{$\mathrm{GSD}=0.75 \mathrm{~mm}$} & \multicolumn{4}{|c|}{$\mathrm{GSD}=0.5 \mathrm{~mm}$} \\
\hline Model overlap [\%] & 90 & 80 & 70 & 60 & 90 & 80 & 70 & 60 & 90 & 80 & 70 & 60 \\
\hline Projected GSD [mm] & 1 & 1 & 1 & 1 & 1 & 1 & 1 & 1 & 0.5 & 0.5 & 0.5 & 0.5 \\
\hline Calculated GSD [mm] & 0.98 & 0.99 & 0.98 & 0.99 & 0.98 & 0.99 & 0.98 & 0.99 & 0.49 & 0.49 & 0.49 & 0.49 \\
\hline Number of images & 33 & 17 & 12 & 9 & 33 & 17 & 12 & 9 & 154 & 83 & 62 & 47 \\
\hline Number of tie points & 16346 & 6541 & 3022 & 960 & 28346 & 12683 & 5872 & 1660 & 92237 & 55524 & 38582 & 27505 \\
\hline Reprojection error [pix] & 0.53 & 0.49 & 0.49 & 0.51 & 0.40 & 0.43 & 0.45 & 0.54 & 0.54 & 0.53 & 0.53 & 0.45 \\
\hline Adjustment time [s] & 62 & 29 & 21 & 15 & 84 & 39 & 24 & 16 & 418 & 197 & 400 & 77 \\
\hline Number of GCPs & 26 & 26 & 24 & 21 & 26 & 26 & 24 & 26 & 26 & 26 & 24 & 26 \\
\hline $\begin{array}{l}\text { Number of check } \\
\text { points }\end{array}$ & 8 & 8 & 8 & 7 & 8 & 8 & 8 & 8 & 8 & 8 & 8 & 8 \\
\hline RMSE on GCPs [mm] & 0.96 & 0.93 & 1.21 & 0.82 & 1.25 & 1.26 & 0.87 & 1.28 & 1.16 & 1.12 & 1.09 & 0.84 \\
\hline $\begin{array}{l}\text { RMSE on check points } \\
{[\mathrm{mm}]}\end{array}$ & 1.14 & 0.98 & 1.18 & 1.99 & 1.34 & 1.24 & 1.06 & 1.51 & 1.75 & 1.38 & 1.34 & 1.03 \\
\hline
\end{tabular}




\section{$-1 \mathrm{~mm}$ resolution \\ $-0.75 \mathrm{~mm}$ resolution

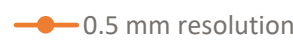

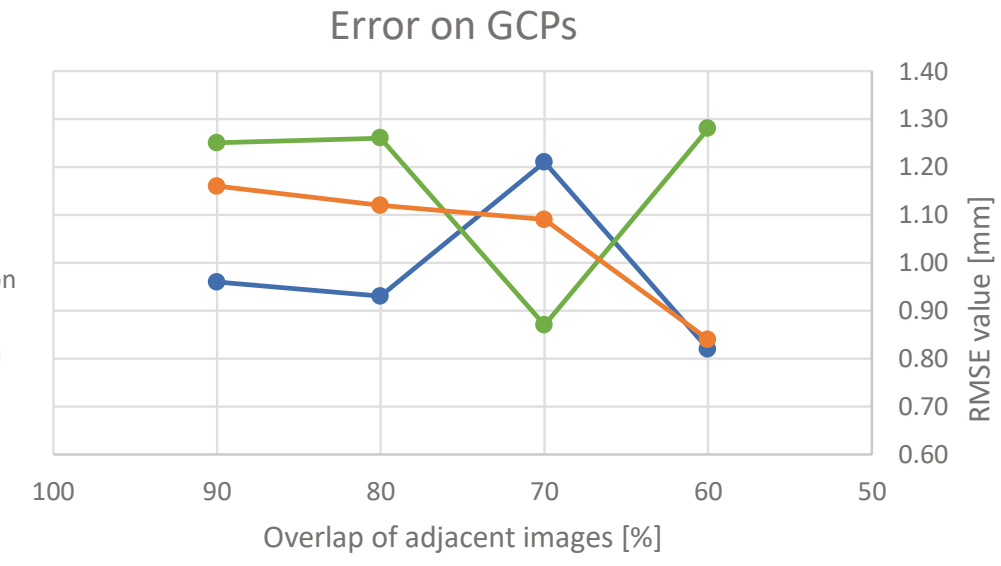

Fig. 5. Error on GCPs for different overlap and image resolution

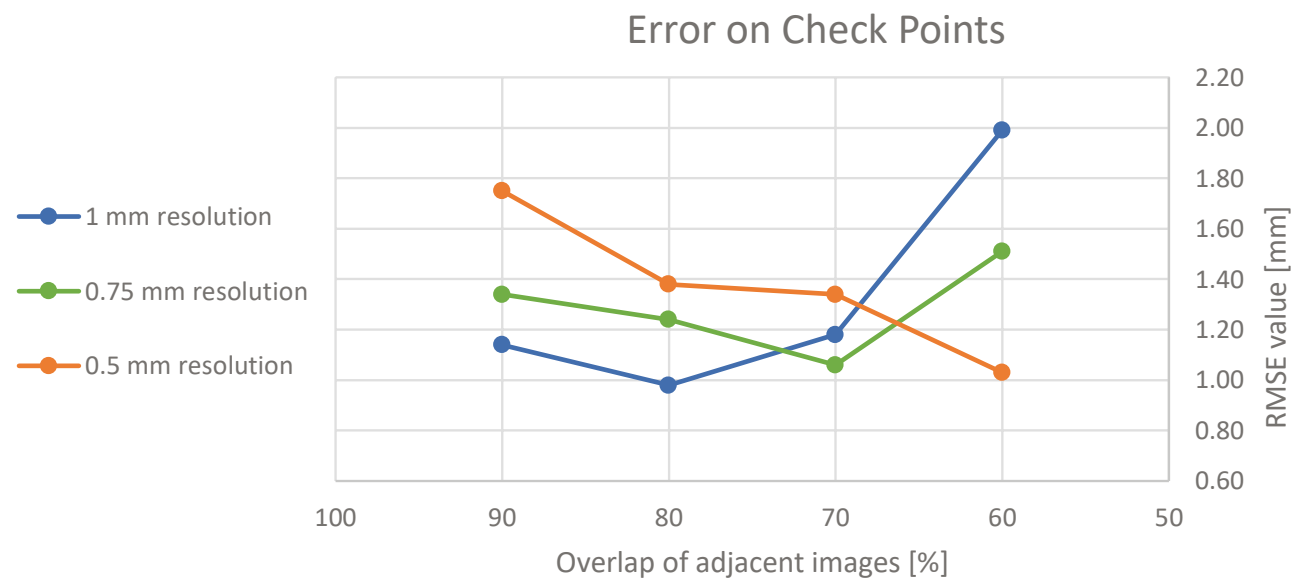

Fig. 6. Error on check points for different overlap and image resolution

Considering the results, it can be stated that all the accuracy values received during the process of aerotriangulation are similar. In the case of GCPs, regardless of the spatial resolution and overlap, discrepancies did not exceed $0.5 \mathrm{~mm}$ and in the case of check points, the maximum difference was $1.01 \mathrm{~mm}$. Furthermore, these results show that the impact of the overlap is not clearly visible. Based on the outcomes, we would not suggest using the highest possible overlap due to geometry conditions of a network, which get worse while implementing a shorter distance between adjacent images. We would suggest taking photos with a $70-80 \%$ overlap, bearing in mind that lower overlap of images taken from a further distance from the object may result in problems with the reconstruction due to the limited number of images. 


\section{Results - Number of GCPs and Check Points}

Further analyses were carried out for the images with $1 \mathrm{~mm}$ spatial resolution overlapping by $90 \%$ and $80 \%$, as this dataset had the best parameters from the point of view of photogrammetry - no great variations in contrast and uniform lighting. Previous analyses were carried out with 26 GCPs and 8 check points. We decided to check how the results would vary if this proportion was disturbed. Hence, the next factor we examined was the number of control points and check points. GCPs were gradually excluded from the aerotriangulation and their function was set to check points. Their distribution remained even throughout the whole process. The last variant concerned implementing two scale bars (sections orienting and scaling the model) on each wall instead of GCPs. We chose 4 points from the GCPs collection and calculated the distances between them based on measured coordinates. The first scale bar had the length of $4.090 \mathrm{~m}$ and the second one was $4.842 \mathrm{~m}$ long. Then, they were excluded both from the set of control points and check points. They were manually marked as tie points serving for establishing the user constraints and the distances between them were given to the software. All remaining 30 points were treated as check points. Such a solution was important to see whether it is possible to replace the coordinates with the distance measured between two characteristic points without the loss of accuracy. It would not be always applicable but in some situations can significantly facilitate the reconstruction process if exact georeferencing is not required. The results of this analysis are presented in Table 3 and in corresponding figures - Figure 7 and Figure 8.

Table 3. Aerotriangulation results regarding number of GCPs and check points

\begin{tabular}{|l|c|c|c|c|c|c|c|c|c|c|c|c|c|c||}
\hline \multicolumn{1}{|c|}{ Parameter } & \multicolumn{9}{c|}{$90 \%$ overlap } & \multicolumn{7}{c||}{$80 \%$ overlap } \\
\hline \hline $\begin{array}{l}\text { Number } \\
\text { of GCPs }\end{array}$ & 26 & 22 & 18 & 14 & 10 & 6 & $\begin{array}{c}4 \\
\text { (scale } \\
\text { bars })\end{array}$ & 26 & 22 & 18 & 14 & 10 & 6 & $\begin{array}{c}\text { (scale } \\
\text { bars) }\end{array}$ \\
\hline $\begin{array}{l}\text { Number } \\
\text { of check points }\end{array}$ & 8 & 12 & 16 & 20 & 24 & 28 & 30 & 8 & 12 & 16 & 20 & 24 & 28 & 30 \\
\hline $\begin{array}{l}\text { RMSE on } \\
\text { GCPs/scale } \\
\text { bars [mm] }\end{array}$ & 0.96 & 0.94 & 0.92 & 0.87 & 0.40 & 0.24 & 0.30 & 0.93 & 0.92 & 0.91 & 0.75 & 0.44 & 0.22 & 0.27 \\
\hline $\begin{array}{l}\text { RMSE on } \\
\text { check points } \\
\text { [mm] }\end{array}$ & 1.14 & 1.12 & 1.42 & 1.58 & 0.90 & 1.53 & 1.64 & 0.98 & 1.04 & 1.36 & 1.48 & 1.45 & 1.75 & 1.68 \\
\hline
\end{tabular}




\section{RMSE on GCPs and check points - $90 \%$ overlap}

- Error on GCPs Error on check points

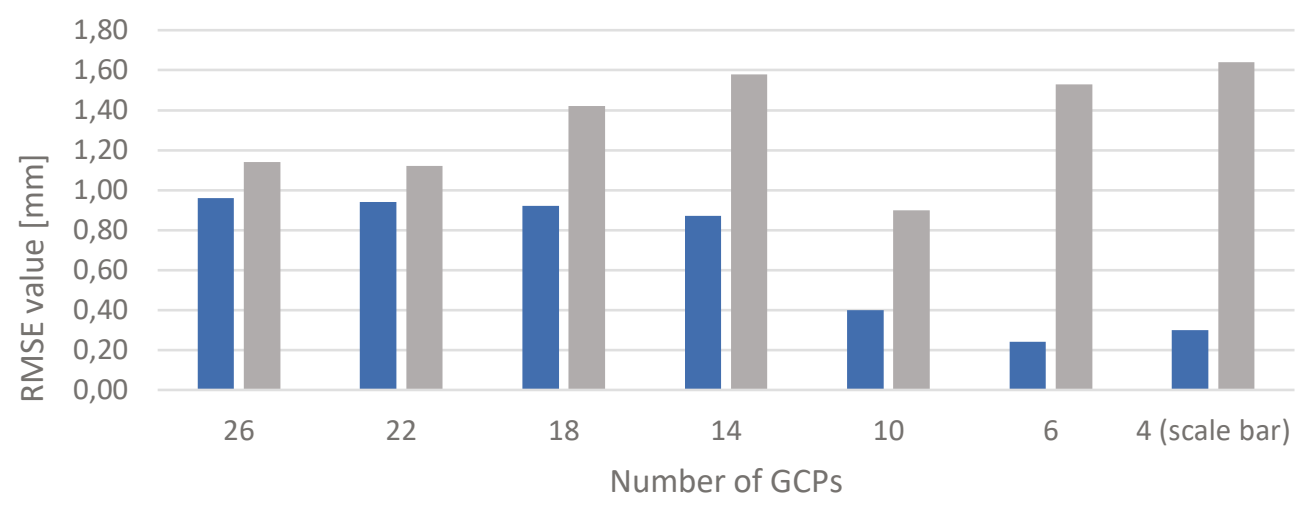

Fig. 7. RMSE values regarding different number of GCPs and $90 \%$ overlap

\section{RMSE on GCPs and check points - $80 \%$ overlap}

Error on GCPs Error on check points

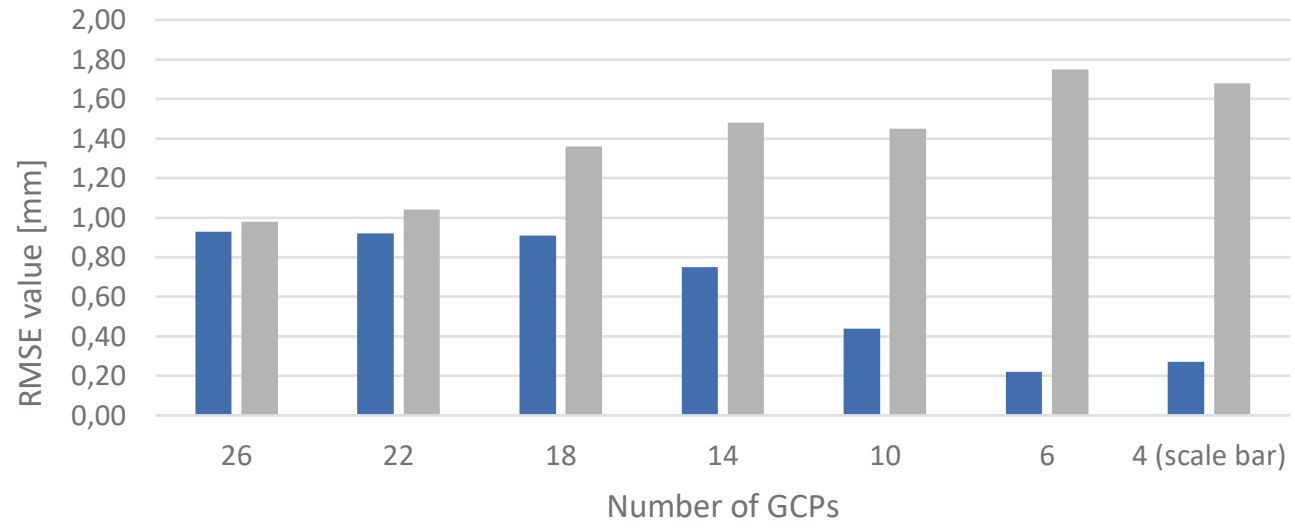

Fig. 8. RMSE values regarding different number of GCPs and $80 \%$ overlap

For both cases, the increased internal accuracy (based on GCPs) can be noticed along with the smaller number of GCPs. It seems quite logical as the number of points to which the model has to be fitted decreases, hence the error value is lower. However, as the number of GCPs increases, the external accuracy is also enhanced. It seems quite coherent and understandable since there are more points referring to real coordinates. It can be stated that the overlap does not correlate with the number of GCPs and check points - error values and pattern remain stable, apart from one 
configuration which might be affected by a random error. Based on the aforementioned analysis, it can be concluded that minimizing the number of control points and limiting it to the classic approach with GCPs distributed in the corner and central areas of an object turns out to be a good strategy. Moreover, if a very high precision of the reconstruction is not required, it is also worth considering the use of scale bars instead of control points as it allows a lot of time to be saved during both works in the field and data processing.

\section{Results - Camera Calibration}

The last aspect that was taken into account in the course of this research was the method of camera calibration and its impact on the final model accuracy. For the photoset of $1 \mathrm{~mm}$ resolution, we implemented the following variants: camera self-calibration and pre-calibration performed in PI-Calib on a test field - with all values kept, only focal length preserved, both focal length and principal point coordinates preserved. We also decided to explore the parameters of internal orientation computed for different photo overlaps during self-calibration. We implemented those values manually for different photosets and calculated the final accuracy. For example, in a photoset with $90 \%$ overlap we set as fixed internal orientation parameters calculated in the self-calibration for a dataset with $90 \%, 70 \%$ and $60 \%$ overlap. The results are presented in Table 4 .

Table 4. Results of aerotriangulation regarding different calibration methods;

FL - focal length, PP - principal point

\begin{tabular}{|c|c|c|c|c|c|c|c|c|c|}
\hline \multirow[t]{2}{*}{$\begin{array}{l}\text { Model } \\
\text { overlap }\end{array}$} & \multirow[t]{2}{*}{$\begin{array}{l}\text { RMSE } \\
\text { values }\end{array}$} & \multirow[t]{2}{*}{$\begin{array}{l}\text { Self-calibration } \\
{[\mathrm{mm}]}\end{array}$} & \multicolumn{3}{|c|}{$\begin{array}{l}\text { PI Calib calibration } \\
\text { [mm] }\end{array}$} & \multicolumn{4}{|c|}{$\begin{array}{l}\text { Overlap variant from which the } \\
\text { internal orientation values were } \\
\text { taken }[\mathrm{mm}]\end{array}$} \\
\hline & & & full & $\mathrm{FL}+\mathrm{PP}$ & $\mathrm{FL}$ & $90 \%$ & $80 \%$ & $70 \%$ & $60 \%$ \\
\hline \multirow[b]{2}{*}{$90 \%$} & GCPs & 0.96 & 36.44 & 5.78 & 3.75 & \multirow[b]{2}{*}{$x$} & 0.93 & 1.11 & 1.42 \\
\hline & $\begin{array}{l}\text { check } \\
\text { points }\end{array}$ & 1.14 & 36.44 & 6.1 & 3.71 & & 1.04 & 1.36 & 1.76 \\
\hline \multirow[b]{2}{*}{$80 \%$} & GCPs & 0.93 & 27.20 & 4.78 & 3.12 & 0.96 & \multirow[b]{2}{*}{$x$} & 1.05 & 1.17 \\
\hline & $\begin{array}{l}\text { check } \\
\text { points }\end{array}$ & 0.98 & 27.12 & 4.14 & 3.54 & 1.08 & & 1.21 & 1.44 \\
\hline \multirow[b]{2}{*}{$70 \%$} & GCPs & 1.21 & 19.47 & 3.97 & 2.18 & 1.23 & 1.23 & \multirow[b]{2}{*}{$\mathrm{x}$} & 1.26 \\
\hline & $\begin{array}{l}\text { check } \\
\text { points }\end{array}$ & 1.18 & 28.94 & 3.47 & 2.33 & 1.04 & 1.13 & & 1.43 \\
\hline \multirow{2}{*}{$60 \%$} & GCPs & 0.82 & 11.09 & 1.61 & 1.61 & 0.81 & 0.80 & 0.82 & \multirow[b]{2}{*}{$\mathrm{x}$} \\
\hline & $\begin{array}{l}\text { check } \\
\text { points }\end{array}$ & 1.99 & 19.76 & 2.32 & 2.02 & 1.8 & 1.79 & 1.83 & \\
\hline
\end{tabular}


The first conclusion that may be derived is the fact that in every single case, the worst values were obtained for camera calibration performed on a test field, although the camera's focal length was stabilized before the camera calibration and preserved during the photo acquisition. Preserving both the focal length and principal point coordinates from the method of pre-calibration and allowing for adjusting other parameters resulted in a much better outcome. It is worth considering that in this method of calibration, the photo groups with the highest overlap, in which a great number of images were processed during aerotriangulation, tend to be affected by more serious errors. The fewer images are taken into consideration during the aerotriangulation, the lower the error values. The problem with camera calibration on a test field may be caused by the lack of a representative data sample gathered during camera calibration and also even the minor changes in the lens's geometry which may have occurred during the transportation of the device and the photo acquisition itself.

Another interesting aspect is the accuracy obtained with the use of the parameters from the self-calibration of the images with different overlap. Self-calibration performed for the particular case gave the best results only for the photo group with $80 \%$ overlap. Internal orientation elements determined for this configuration allowed for slightly better results in other options. In contrary to the pre-calibration method, in the case of self-calibration the use of the parameters derived from the photosets overlapping by $70 \%$ and $60 \%$ resulted in lower final accuracy.

According to these results, we would suggest performing self-camera calibration and, if possible, conducting it with the highest possible number of the images and then implementing obtained values in the proper dataset consisting of the smaller number of photographs. It is worth mentioning that the aerotriangulation with self-calibration is not the process of calibrating the camera itself but the whole photo group. That is probably why those parameters tend to produce better results. Camera pre-calibration performed on a test field may deliver inaccurate values, especially in the case of digital, mobile, hand-held cameras whose lens's geometry stability is provided by e.g. adhesive tape disabling the lens's movement.

\section{Results - Visual Issues}

In the last analysis we decided to assess how overlap and resolution affects the visual accuracy of a mesh model and the time of its generation. The visual analysis was carried out on the photosets with $0.75 \mathrm{~mm}$ and $1 \mathrm{~mm}$ with different overlap and one model based on $0.5 \mathrm{~mm}$ photographs with $60 \%$ overlap as this was the only one where the process of model texturizing was successful. Such problems might have been caused by too large volume of the photoset or too many similar images. A visual analysis revealed the problems of non-uniform lighting and shadowing which are visible on mesh models. Since the photographs were taken from just one distance, 
without additional photographs of details, protruding elements such as metal rods were not correctly reconstructed. A difference in the level of detail between variants of $0.5 \mathrm{~mm}, 0.75 \mathrm{~mm}$ and $1 \mathrm{~mm}$ is visible. As expected, the best results were achieved for $0.5 \mathrm{~mm}$ and $0.75 \mathrm{~mm}$, however this difference is relatively small. The worst visual accuracy, but still satisfying, was produced for the images of $1 \mathrm{~mm}$ resolution. The time needed to reconstruct the model varied according to the number of images in the dataset. For 9 images the process took approximately 40 minutes and for 40 images - over two hours. Interestingly, within the analyses of one resolution but different overlap values, we were not able to detect significant differences. This observation might be particularly important for potential users.

\section{Discussion}

We managed to find several papers concerning similar issues and aimed at the assessment of the impact of particular factors on the accuracy of a reconstructed model. Most frequently, the analysis concerned UAV images but the method and software remained the same for both approaches.

The camera calibration aspect is thoroughly discussed in [28]. The authors test different variants for the calibration of UAV images - three methods involve pre-calibration with different software and the fourth one uses camera self-calibration. The results are divided according to the assumed accuracy of GCPs measurements. However, there cannot be found such a striking difference between pre-calibration and self-calibration. This may lead to the conclusion that pre-calibration in the case of the presented research was not conducted properly or the parameters of the camera were disturbed during transportation and photo acquisition. Nevertheless, in the majority of variants described in the aforementioned paper, the accuracy was also better for self-calibration.

The issue of number and distribution of GCPs is measured under different circumstances in several papers, e.g. [29-31]. However, it is hard to refer the results presented in our article to those from the aforementioned papers as they all concern UAV imagery. Control point distribution for the purpose of aerial imagery, even with the use of the SfM, is different due to the characteristics of reconstructed objects, their size, accessibility and much shorter distance to the object in close-range photogrammetry. Villanueva and Blanco proved in their paper [30] that the increased number of GCPs triggers higher both internal and external accuracy which does not correspond to the results obtained in our study. This might be connected to their density with reference to the size of the object as they used 25 GCPs for the whole site surveyed with UAV and we used 26 GCPs for a much smaller object. However, the results obtained in [30] correspond to those presented in our article. The authors claim that smaller number of control points results in higher internal accuracy as there are fewer geometrical restrictions to which the model has to adapt. At the same 
time, the error values on check points became extremely high when fewer control points were included in their analysis.

During the analysis we also noticed that the assumed accuracy of control points measurement had a big impact on the accuracy values. This issue was not further explored during the research but after test calculations we noticed that lower than real assumed accuracy of control points resulted in much worse accuracy parameters and higher accuracy produced highly unstable and unpredictable results. We decided to note that the correct assessment of the accuracy of measurements performed in the field may be another key factor.

The study presented in our article certainly does not fully explore the scope of research in the field of ground photo network optimization performed with a hand-held digital camera. We are aware of the fact that it might be worth carrying out further research, e.g. to check if the results are similar for different types of objects. It would also be relevant to test other camera devices. It is worth noting that the results obtained during this research, even those with the weakest accuracy, still reflects the geometry of the object very precisely. For the usage in many domains, it does not matter so much, whether the external accuracy of a model is at the level of 1 or $2 \mathrm{~mm}$, as this is still a very good result.

\section{Conclusions}

The aim of this study was to assess the impact of different parameters on the accuracy of a 3D model reconstruction based on images taken with a hand-held digital camera. The object of the research was an architectural object of a cultural heritage value - the base of the former monument to Ivan Konev in Kraków. The analyzed factors were: overlap, number of ground control points, and method of camera calibration and resolution of images. The research was conducted in the Bentley ContextCapture software using the SfM algorithm.

It was observed that, in spite of the recommendation to use as high an overlap as possible, which results from the nature of the SfM algorithms, it does not seem to be the best, generally-applicable practice. According to the results, we would suggest implementing photographs overlapping by $70-80 \%$. In the case of bad lighting conditions or a small number of images it would be recommended to use higher overlap to minimize the risk of aerotriangulation failure. During the visual assessment of models, it seems that the overlap does not significantly affect the visual aspect, but rather the resolution plays a key role. The study on the number of control points revealed that along with a smaller number of GCPs, internal accuracy increases. At the same time, the external accuracy decreased with a smaller number of control points. We also noticed that it could be possible to replace total station or GPS measurements with implementing simple scale bars, if precise coordinates measurements are not required as the accuracy in that configurations dwindled 
by not more than $1 \mathrm{~mm}$. We would suggest in such cases applying higher overlap between images in order to provide more redundant measurements. It seems that the optimal number of control points coincides with a general rule implemented by photogrammetry: distributing control points evenly throughout the whole region of study including the corners and central area. It is also important to correctly assess the accuracy of measurements carried out in the field. According to the analysis of camera calibration the best solution seems to be self-calibration of the camera. Pre-calibration in the case of our study produced the worst results for every analyzed variant. It is important to note that the process of pre-calibration might have been affected by an unknown error as no other researchers noticed such a striking difference during their works. However, it is often suggested to use self-calibration as during that process the camera itself is not calibrated but the whole group of images taken with exactly the same parameters.

At the point of summarizing this research, we believe it is important to pay attention to several factors which were problematic during the course of this research, and which probably could have been eliminated. First of all, the day of photo acquisition should be cloudy, which provides stray lighting. If it is not possible, the time of a day should be adjusted so that trees, high buildings etc. not cause shadowing and differences in contrast on the object of research. We would also suggest that pre-calibration of the camera, if necessary, should be performed just before or just after the photo acquisition, in the same place and with the same lens parameters. It is also important to carefully choose the distance to the reconstructed object with reference to the expected level of detail. In many cases it would also be necessary to take some images from a much shorter distance and at different angles to supplement the original network with additional photographs of details and smaller elements, providing tie points between all the images.

Undoubtedly, in order to perform 3D model reconstruction effectively, optimize the photo network and save time both during works in the field and data processing, it is important to devote some time to planning the photo acquisition. This would involve calculating the distance between images, providing the desired overlap and the distance to the object itself constituting the photo resolution. Such activities allow for reducing the redundancy of data, which may significantly reduce the time consumption of the process and without negatively affecting the accuracy of the final model. The research showed that even small differences in the parameters settings and values may change the results. Hence, it seems that, in case of any problems, it would be recommended to make several attempts at the same dataset in order to find the most suitable variant. Users should bear in mind that every photo group is different and acts in a slightly different way. Sometimes even deleting one image may positively affect the final accuracy of aerotriangulation.

To sum up, photogrammetric software using the SfM algorithm is a powerful tool which allows users to perform 3D model reconstruction. The accuracy of the final result is high, which makes this software suitable for various purposes. It is 
possible to minimize time and effort of the software users without negative impact on the accuracy. Reconstructed models such as mesh models or orthophotomaps can be used in many different fields of science, e.g., architecture, archeology, urban planning, cultural heritage and even space research and medicine. They may successfully replace or supplement traditional methods based on classical surveys and terrestrial or aerial laser scanning.

\section{References}

[1] Hellman T., Lahti M.: Photogrammetric 3D modeling for virtual reality. 2018. https://www.researchgate.net/publication/327227913 [access: 28.11.2020].

[2] Oats R.C., Escobar-Wolf R., Oommen T.: A novel application of photogrammetry for retaining wall assessment. Infrastructures, vol. 2, no. 3, 2017, pp. 1-12. https://doi.org/10.3390/infrastructures2030010.

[3] Roncella R., Re C., Forlani G.: Performance Evaluation of a Structure and Motion Strategy in Architecture and Cultural Heritage. ISPRS - International Archives of the Photogrammetry, Remote Sensing and Spatial Information Sciences, vol. XXXVIII-5, March 2012, pp. 285-292. https://doi.org/10.5194/isprsarchives-xxxviii-5-w16-285-2011.

[4] Green S.: A Comparative Assessment of Structure from Motion Methods for Archaeological Research. Journal of Archaeological Science, vol. 46, June 2014, pp. 173-181. https://doi.org/10.1016/j.jas.2014.02.030.

[5] Samaan M., Deseilligny M.P., Heno R., De La Vaissière E., Roger J.: Close-range photogrammetric tools for epigraphic surveys. Journal on Computing and Cultural Heritage, vol. 9, no. 3, 2016, pp. 1-18. https://doi.org/10.1145/2966985.

[6] Cignetti M., Godone D., Wrzesniak A., Giordan D.: Structure from Motion Multisource Application for Landslide Characterization and Monitoring: The Champlas du Col Case Study, Sestriere, North-Western Italy. Sensors (Switzerland), vol. 19, no. 10, 2019, art. no. 2364. https://doi.org/10.3390/s19102364.

[7] Medjkane M., Maquaire O., Costa S., Roulland Th., Letortu P., Fauchard C., Antoine R., Davidson R.: High-resolution monitoring of complex coastal morphology changes: cross-efficiency of SfM and TLS-based survey (Vaches-Noires cliffs, Normandy, France). Landslides, vol. 15, no. 6, 2018, pp. 1097-1108. https://doi.org/10.1007/s10346-017-0942-4.

[8] Verma A.K., Bourke M.C.: A method based on structure-from-motion photogrammetry to generate sub-millimetre-resolution digital elevation models for investigating rock breakdown features. Earth Surface Dynamics, vol. 7, no. 1, 2019, pp. 45-66. https://doi.org/10.5194/esurf-7-45-2019. 
[9] Widya A.R., Monno Y., Imahori K., Okutomi M., Suzuki S., Gotoda T., Miki K.: 3D Reconstruction of Whole Stomach from Endoscope Video Using Structure-from-Motion. [in:] 2019 41st Annual International Conference of the IEEE Engineering in Medicine and Biology Society (EMBC), IEEE, Berlin, Germany, 2019, pp. 3900-3904. https://doi.org/10.1109/EMBC.2019.8857964.

[10] Hussien D.A., Abed F.M., Hasan A.A.: Stereo photogrammetry vs computed tomography for 3D medical measurements. Karbala International Journal of Modern Science, vol. 5, no. 4, 2019, pp. 201-212. https://doi.org/10.33640/2405609X.1130.

[11] Chiabrando F., Donadio E., Rinaudo F.: SfM for orthophoto generation: A winning approach for cultural heritage knowledge. International Archives of the Photogrammetry, Remote Sensing and Spatial Information Sciences - ISPRS Archives, vol. XL-5/W7, 2015, pp. 91-98. https://doi.org/10.5194/isprsarchives-XL-5-W7-91-2015.

[12] Lewińska P., Pargieła K.: Comparative Analysis of Structure-From-Motion Software's - An Example of Letychiv (Ukraine) Castle and Convent Buildings. Journal of Applied Engineering Sciences, vol. 8, no. 2, 2019, pp. 73-78. https://doi.org/10.2478/jaes-2018-0021.

[13] Brandolini F., Patrucco G.: Structure-from-Motion (SFM) Photogrammetry as a Non-Invasive Methodology to Digitalize Historical Documents: A Highly Flexible and Low-Cost Approach? Heritage, vol. 2, no. 3, 2019, pp. 2124-2136. https://doi.org/10.3390/heritage2030128.

[14] Sergeeva A.D., Sablina V.A.: Using structure from motion for monument 3D reconstruction from images with heterogeneous background. [in:] 2018 7th Mediterranean Conference on Embedded Computing (MECO), IEEE, Budva, Montenegro, 2018, pp. 1-4. https://doi.org/10.1109/MECO.2018.8406058.

[15] Bekele M.K., Pierdicca R., Frontoni E., Malinverni E.S., Gain J.: A survey of augmented, virtual, and mixed reality for cultural heritage. Journal on Computing and Cultural Heritage, vol. 11, no. 2, 2018, art. no. 7. https://doi.org/10.1145/3145534.

[16] Miles H.C., Wilson A., Labrosse F. et al.: Alternative representations of $3 D$-reconstructed heritage data. Journal on Computing and Cultural Heritage, vol. 9, no. 1, 2015, art. no. 4. https://doi.org/10.1145/2795233.

[17] ContextCapture. Quick guide for photo acquisition. Bentley, 2016.

[18] Agisoft Metashape User Manual. Agisoft LLC, 2019.

[19] Micheletti N., Chandler J.H., Lane S.N.: Structure from Motion (SfM) Photogrammetry. Geomorphological Techniques, vol. 2, sec. 2.2, 2015, pp. 1-12.

[20] Kwiatek K., Tokarczyk R.: Immersive photogrammetry in 3D modelling. Geomatics and Environmental Engineering, vol. 9, no. 2, 2015, pp. 51-62. https://doi.org/10.7494/geom.2015.9.2.51. 
[21] Westoby M.J., Brasington J., Glasser N.F., Hambrey M.J., Reynolds J.M.: 'Structure-from-Motion' photogrammetry: A low-cost, effective tool for geoscience applications. Geomorphology, vol. 179, December 2012, pp. 300-314. https://doi.org/10.1016/j.geomorph.2012.08.021.

[22] Verhoeven G.J.J.: Taking computer vision aloft - Archaeological three-dimensional reconstructions from aerial photographs with PhotoScan. Archaeological Prospection, vol. 18(1), 2011, pp. 67-73.

[23] Shah Y., Raut S., Wadle S., Patil S.: A Study of Structure from Motion Photogrammetry for Generating 3D Model from 2D Images. IOSR Journal of Engineering, vol. 4, 2018, pp. 72-76.

[24] Nyimbili P.H., Demirel H., Seker D.Z., Erden T.: Structure from Motion (SfM) Approaches and Applications. [in:] Spatial Data Processing, Modelling, Analysing and Management for Knowledge Based Systems, International Scientific Conference on Applied Sciences, 27-30 September 2016 - Antalya, Turkey, 2016.

[25] PHOTOMOD 6.2 User manual Processing of UAS data.

[26] Zomrawi N., Hussien M.A., Mohamed H.: Accuracy evaluation of digital aerial triangulation. International Journal of Engineering and Innovative Technology, vol. 2, no. 10, 2013, pp. 7-11.

[27] Khoshelham K.: Role of tie points in integrated sensor orientation for photogrammetric map compilation. Photogrammetric Engineering and Remote Sensing, vol. 75, no. 3, 2009, pp. 305-311. https://doi.org/10.14358/PERS.75.3.305.

[28] Harwin S., Lucieer A., Osborn J.: The impact of the calibration method on the accuracy of point clouds derived using unmanned aerial vehicle multi-view stereopsis. Remote Sensing, vol. 7, no. 9, 2015, pp. 11933-11953. https://doi.org/10.3390/ rs70911933.

[29] Oniga E., Breaban A.I., Florian S.: Determining the Optimum Number of Ground Control Points for Obtaining Determining the optimum number of ground control points for obtaining high precision results based on UAS images. Proceedings, vol. 2, no. 7, 2018, art. no. 352. https://doi.org/10.3390/ecrs-2-05165.

[30] Sanz-Ablanedo E., Chandler J.H., Rodríguez-Pérez J.R., Ordóñez C.: Accuracy of Unmanned Aerial Vehicle (UAV) and SFM photogrammetry survey as a function of the number and location of ground control points used. Remote Sensing, vol. 10, no. 10, 2018, art. no. 1606. https://doi.org/10.3390/rs10101606.

[31] Villanueva J.K.S., Blanco A.C.: Optimization of Ground Control Point (GCP) Configuration for Unmanned Aerial Vehicle (UAV) Survey Using Structure from Motion (SFM). International Archives of the Photogrammetry, Remote Sensing and Spatial Information Sciences, vol. XLII-4/W12, 2019, pp. 167-174.

[32] Torres-Sánchez J., López-Granados F., Borra-Serrano I., Manuel Peña J.: Assessing UAV-collected image overlap influence on computation time and digital surface model accuracy in olive orchards. Precision Agriculture, vol. 19, no. 1, 2018, pp. 115-133. https://doi.org/10.1007/s11119-017-9502-0. 
[33] Czarnecka D.: Z Krakowa do Kirowa. O pomniku Iwana Koniewa w latach 1987-1991. Res Gestae. Czasopismo Historyczne, vol. 12, 2012, pp. 204-226.

[34] Stachnik P.: Koniew w Krakowie. Ani miasta nie ocalit, ani na cokole dtugo nie postat. Nasza Historia, 29.12.2016. https://naszahistoria.pl/koniew-w-krakowieani-miasta-nie-ocalil-ani-na-cokole-dlugo-nie-postal/ar/11659862 [access: 20.05.2020].

[35] PI-Calib. Operation Manual Camera Calibration Software. TOPCON. http://www.terrageomatics.com/downloads/PI-calib-manual.pdf [access: 28.11.2020]. 